\title{
Game Model on the Governmental Decision in River Basin Ecological Protection
}

\author{
Xian-shi $\mathrm{LI}^{1,2, \mathrm{a}}$, Jian $\mathrm{LI}^{1, \mathrm{~b}}$ \\ ${ }^{1}$ School of Management and Economics, Beijing Institute of Technology, Beijing, 100081, China \\ ${ }^{2}$ School of Business, Shijiazhuang University of Economics, Shijiazhuang, 050031, China \\ a email: leexianshi@163.com, ${ }^{\mathrm{b}}$ email: lijianbit@bit.edu.cn
}

Keywords:Game model; Nash equilibrium; Principal-agent; Decision-making;River basin ecology

\begin{abstract}
It is a principal-agent relationship in the process of the implementation of river basin ecological protection, which causes the game between the different governments inevitably. Game theory can explain the decision makers' behavior under specific conditions. From analyzing the game model, it finds the Nash equilibrium under the different conditions between the central government and the local government. It is discussed how non-cooperative game might not be optimal for the whole system and how decision makers can make decisions based on self interests. Providing complete information and increasing the punishment probability, improving the incentive mechanism and reforming the local government's performances evaluation in the future might help change behavior and decisions to make the stakeholders cooperative.
\end{abstract}

\section{Introduction}

With the degraded water quality and pollution of the rivers, conflicts often arise when different water and environmental users compete for a limited water supply, especially in the watershed zone. In China, for water resources the state applies the system under which management of river basins is combined with management of administrative regions. The administrative department of the water under the State Council is responsible for unified management and supervision throughout the country. The local people's governments within the limits of their specified powers are responsible for unified management and supervision over the water resources. The state formulates strategic plans for the water resources and the river ecology across the land. The plans for a region within a river basin shall be subordinated to the plans for the river basin. The central government is the principal, and the local governments are the agents for getting the information of the watershed ecology more fully. Because it takes the scale of investment and the growth rate of GDP as the core performance criteria, the local governments will try to accelerate the regional economic growth. So, the local governments won't implement the central government policies for water resources protection usually. The results of governing the river water resources are not very ideal. Here we use game theory to analyze the problem.

Game theory is shown in the literature to be a useful approach to resolve the watershed ecology conflicts $^{[1]}$. Games are decision problems with multiple players whose decisions impact one another. Game theory is divided into two general branches: cooperative and non-cooperative games. In the river ecological governance, we should get the reasons why the central government and the local governments choose the cooperative or non-cooperative strategies.

\section{Model constructions}

Players.In this paper, we will divide the numerous governments into two categories: the central government and the local government. The central government that refers to the State Council and the department of water administration represents national interests. The local government (both the provincial governments and the county governments) refers to the local governments and administrative departments of watershed.

Strategies.Game strategies refer to the two kinds of governments action rules in the river water 
resources governance ${ }^{[2]}$. As the representative of public interests, the central government's strategies are to maximize the interests of the whole basin. The central government has two strategies to supervise the implementation of water resources policies formulated by the state: supervision and no supervision. If it is found that the local government doesn't implement the policies of water protection, the central government will punish the local government. The local government has two strategies: implementation and no implementation.

Model assumptions ${ }^{[3]}$. The first assumption is that the players are involved in the central government and the local government. The central government and the departments of water administration actions represent the biggest utility of the whole basin. The local government and the departments of water administration actions are on behalf of the local region in the utility. Of course, in the real life, there are different games between the different levels of government actions, but we don't discuss it anymore. The second assumption is the hypothesis of "economic man". The central government and local government are rational "economic man"; their pursuits are maximizing their own interests. The third assumption is computable of the ecological benefit. In order to facilitate research, we assume that the payoffs are computable.

\section{Game models}

Game model with complete information. Assumed the local government return is B when it won't execute the governance policy, $\mathrm{B}_{2}$ is the central government revenue; when it executes the governance policy, the return is $b-\mathrm{B}$ and the central government revenue is $\mathrm{B}_{1}$. If the central government often regulates the local government, and the supervision cost is $\mathrm{C}$, it will impose a punishment when the local government doesn't implement the protection policy. When the river is polluted because of the central government without supervision and punishment, the central government's losses are $\mathrm{C}_{1}$. When the local government is punished by the penalties, the losses are $\mathrm{C}_{2}$. The game between the two players is shown in figure 1 :

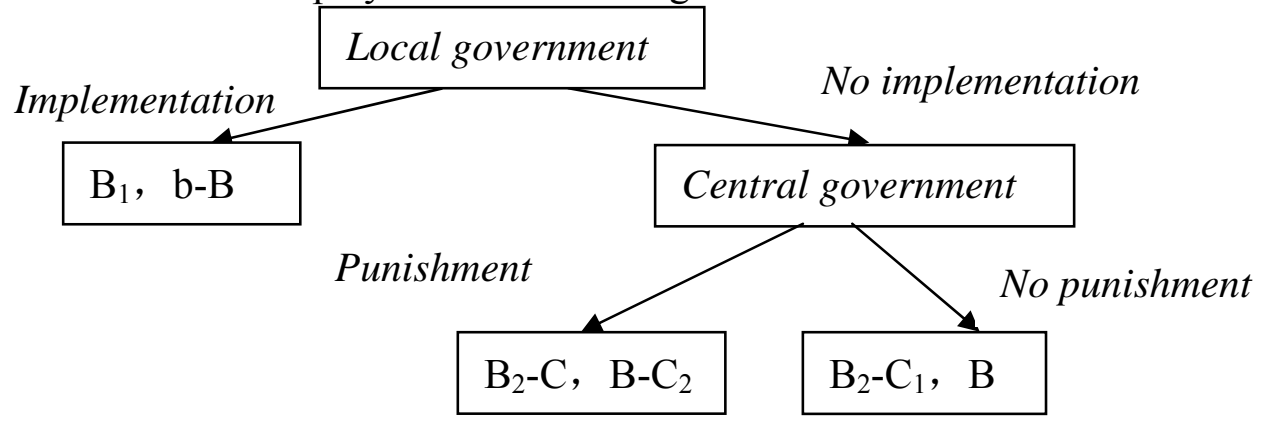

Fig. 1 Dynamic game model with complete information of the two governmental players

In the game process, if the local government chooses the implementation policy, the two players will end the game. In fact, the local government chooses the no implementation strategy from its own interests. Next, the central government will weigh $\mathrm{B}_{2}-C$ and $\mathrm{B}_{2}-C_{1}$ If $C_{1}>C$, the central government will increase the supervision and punishment. At this time, the local government will compare $b-\mathrm{B}$ and $\mathrm{B}-C_{2}$.if $\mathrm{B}>\left(b+C_{2}\right) / 2$, the local government will deceive the central government, so the game equilibrium is punishment and no implementation, which is a non-cooperative game equilibrium. As we can see, if the local government executes protection policy, it must make the local government's costs of fraud outweigh the benefits. i.e. $\mathrm{B}<\left(b+C_{2}\right) / 2 . \mathrm{C}_{2}$ depends on the central government's current policies and systems of punishment. Therefore, to define the local government environmental responsibilities and increase the costs of default are the preconditions for cooperative strategy.

Game model with incomplete information. It assumes that the utility function of the central government and the local government is a linear function. ${ }^{[4]}$ The central government implements watershed management policy A. The central and local government utility probabilities are $\alpha$ and $1-\alpha$ respectively. $\beta$ is the degree coefficient of the local government breaking the rules. $\gamma$ is the utility coefficient of local government breaking the rules. If local government implements the 
central government's policies, the central government utilities are $\mathrm{E}_{z}=\alpha \times \mathrm{A}$, and local government utilities are $\mathrm{E}_{d}=(1-\alpha) \times \mathrm{A}$.

We assume that local government implements the policies completely, here $\beta=0$.If the central government does not supervise, so the utilities for local government are $\mathrm{E}_{d}=(1-\alpha) \times \mathrm{A}(0 \leq \alpha \leq 1)$, the central government utilities are $\mathrm{E}_{z}=\alpha \times \mathrm{A}(0 \leq \alpha \leq 1)$.If the central government supervises the local government, the local government's utilities are $\mathrm{E}_{d}=(1-\alpha) \times \mathrm{A}(0 \leq \alpha \leq 1)$, the central government's utilities are $\mathrm{E}_{z}=\alpha \times \mathrm{A}-C(0 \leq \alpha \leq 1)$. $\mathrm{C}$ is the supervision cost.

We assume that local government implements the policies incompletely. i.e. $\beta \neq 0$.If local government's violation is $\mathrm{Q}$, the central government losses are $Q \times \beta \times \mathrm{A}$. If the central government does not supervise and punishment, so the utilities are $\mathrm{E}_{z}=\alpha \times \mathrm{A} \times(1-\beta)-Q \times \beta \times \mathrm{A}$, the local government utilities are $\mathrm{E}_{d}=(1-\alpha) \times \mathrm{A} \times(1-\beta)+\gamma \times \beta \times \mathrm{A}$. If the central government implements the supervision and punishment, and gives $\mathrm{N}$ times punishment, the local government utilities are $\mathrm{E}_{d}=(1-\alpha) \times \mathrm{A} \times(1-\beta)-(\mathrm{N}-1) \times \gamma \times \beta \times \mathrm{A}$, the central government utilities are $\mathrm{E}_{\mathrm{z}}=\alpha \times \mathrm{A} \times(1-\beta)+\mathrm{N} \times Q \times \beta \times \mathrm{A}-C$. Of course, if the supervision fails, the local government's utilities are $\mathrm{E}_{d}=(1-\alpha) \times \mathrm{A} \times(1-\beta)+\gamma \times \beta \times \mathrm{A}$, and the central government utilities will be reduced due to the cost of supervision, $\mathrm{E}_{z}=\alpha \times \mathrm{A} \times(1-\beta)-Q \times \beta \times \mathrm{A}-C$.

If the local government's probability of breaking the regulations is $P_{d}$, the central government's supervisory probability is $\mathrm{P}_{\mathrm{z}}$, punishment probability is $\mathrm{P}_{\mathrm{f}}$. In the condition of supervision, the central government's utilities are: $U_{z 1}=\mathrm{P}_{d} \times\left\{\mathrm{P}_{f} \times[\alpha \times \mathrm{A} \times(1-\beta)+\mathrm{N} \times Q \times \beta \times \mathrm{A}-C]+\left(1-\mathrm{P}_{f}\right) \times[\alpha \times \mathrm{A} \times(1-\beta)-Q \times \beta \times \mathrm{A}-C]\right\}$ $+\left(1-\mathrm{P}_{d}\right) \times\left[\mathrm{P}_{f} \times(\alpha \times \mathrm{A}-C)+\left(1-\mathrm{P}_{f}\right) \times(\alpha \times \mathrm{A}-C)\right]$; In the condition of no punishment, the central government's utilities are $U_{z 2}=\mathrm{P}_{d} \times[\alpha \times \mathrm{A} \times(1-\beta)-Q \times \beta \times \mathrm{A}]+\left(1-\mathrm{P}_{d}\right) \times \alpha \times \mathrm{A} . \mathrm{U}_{\mathrm{z1}}=\mathrm{U}_{\mathrm{z} 2}$ is the optimal probability of local government's illegal activities. The probability is $\mathrm{P}_{d}=C \div\left[\mathrm{P}_{f} \times Q \times \beta \times \mathrm{A} \times(1+\mathrm{N})\right]$.

In the condition of the supervisory probability is $\mathrm{P}_{\mathrm{z}}$, the local government's illegal utilities are $\quad Y_{d 1}=\mathrm{P}_{z} \times\left\{\mathrm{P}_{f} \times[(1-\alpha) \times \mathrm{A} \times(1-\beta)-(\mathrm{N}-1) \times \gamma \times \beta \times \mathrm{A}]+\left(1-\mathrm{P}_{f}\right) \times[(1-\alpha) \times \mathrm{A} \times(1-\beta)+\gamma \times \beta \times \mathrm{A}]\right\}$ $+\left(1-\mathrm{P}_{z}\right) \times[(1-\alpha) \times \mathrm{A} \times(1-\beta)+\gamma \times \beta \times \mathrm{A}]$; In the condition of executing governance policy, the local government's utilities are: $\mathrm{Y}_{d 2}=(1-\alpha) \times \mathrm{A}$. Counting the function $\mathrm{Y}_{\mathrm{d} 1}=\mathrm{Y}_{\mathrm{d} 2}$, the optimal probability and supervision of the central government will be obtained: $\mathrm{P}_{\mathrm{z}}=[\gamma-(1-\alpha)] \div\left(\mathrm{P}_{f} \times \mathrm{N} \times \gamma\right)$.

To sum up, the Nash equilibriums of the mixed strategy are:

$$
\begin{aligned}
& \mathrm{P}_{d}{ }^{*}=C \div\left[\mathrm{P}_{f} \times Q \times \beta \times \mathrm{A} \times(1+\mathrm{N})\right] . \\
& \mathrm{P}_{z}^{*}=(\gamma+\alpha-1) \div\left(\mathrm{P}_{f} \times \mathrm{N} \times \gamma\right) .
\end{aligned}
$$

From (1) and (2), it can get some results:

if $\mathrm{P}_{d}>\mathrm{P}_{d}{ }^{*}$, the central government's optimal choices are the supervision and punishment. Here $\mathrm{P}_{z}^{*}=1$, so $\mathrm{P}_{f}{ }^{*}=(\gamma+\alpha-1) \div(\mathrm{N} \times \gamma)$. In the condition of $\mathrm{P}_{f}{ }^{*}<\mathrm{P}_{f}$, the central government's punishment probability is larger than the optimal probability, and the local government will choose the implementation strategy certainly; If $\mathrm{P}_{d}<\mathrm{P}_{d}{ }^{*}$, the central government's optimal choice is no supervision. Here $\mathrm{P}_{z}{ }^{*}=0$, so $(1-\alpha)=\gamma$. The local government will choose the implementation from the maximum income by comparing the implementation utilities with the violations; If $\mathrm{P}_{d}=\mathrm{P}_{d}{ }^{*}$, the choices of supervision and no supervision for the central government are no differences.

If $\mathrm{P}_{z}^{*}<\mathrm{P}_{z},\left(\mathrm{P}_{\mathrm{z}}{ }^{*}\right.$ is the optimal probability of the central government supervision), then the local government's optimal choice is pollution control; if $\mathrm{P}_{z}^{*}>\mathrm{P}_{z}$, the local government's optimal choice is not controlled the pollution. According to $\mathrm{P}_{z}{ }^{*}=(\gamma+\alpha-1) \div\left(\mathrm{P}_{f} \times \mathrm{N} \times \gamma\right)$, it is shown that $\mathrm{P}_{\mathrm{z}}{ }^{*}$ decreases with the increase of $\mathrm{P}_{\mathrm{f}}$ and $\mathrm{N}$. That is to say, the central government's optimal supervision 
probability decreases with increasing punishment probability and penalty coefficient. So, the central government should increase the quality of supervision to improve the punishment probability, and improve the penalty coefficient, which can reduce the supervision frequency.

The optimal probability of the local government's illegal operations is $\mathrm{P}_{d}{ }^{*}=C \div\left[\mathrm{P}_{f} \times Q \times \beta \times \mathrm{A} \times(1+\mathrm{N})\right]$. We can see that $\mathrm{P}_{\mathrm{d}}{ }^{*}$ increases with increasing the supervision $\operatorname{cost} \mathrm{C}$, and decreases with increasing $\mathrm{P}_{\mathrm{f}}$ and $\mathrm{N}$. From the above analysis, increasing the punishment probability and the penalty coefficient can reduce the probability of local government's frauds.

\section{Policy implications}

By analyzing the behaviors of the central government and local government from the perspective of the static and dynamic game, it can give some policy implications:

First, establishing the cooperation mechanism is the best way to improve the cooperation for central government and the local government ${ }^{[5]}$. Because the different governments have different utility functions, "prisoner's dilemma" is the real game in the cooperative game ${ }^{[6]}$. Therefore, from a policy perspective, improving the incentive mechanism for the local government can solve the existing problems of inconsistent benefits. The central government can take the regulations and controls to achieve the mutual compensation of river basin ecological benefits through the transfer payment the ecological compensation and other methods, which promote collaboration among the local government and the central government.

Second, it should improve and define the different governments' authorities of river basin water resources management. In spite of the environmental protection law clearly points out that the local people's governments should be responsible for the quality of the environment, "opportunism" and "free-rider problems" must exist because many departments are involved in the river basin management. In addition, watershed is a complex system, and if the upstream or downstream has been polluted, it will affect other administrative regional water quality. If there is no effective authority definition, penalties for the pollution are not very clear. Therefore, the central government should take the local government's interests into account to govern the watershed, and reasonable define the interests and responsibilities for the local government.

Third, the central government should strengthen the supervision, and improve the national supervision mechanism gradually. From the models, we can get the conclusion that the local government's optimal choice must be the implementation if the central government supervises the river protection and punishes severely. Effective supervision and punishment will increase the deceptive cost for the central government. The feasible approach is to establish the national supervision mechanism. Therefore, the construction of a supervision and governance platform can reduce the supervision cost, for it can transfer the information to the supervision department smoothly. So the central government will solve the pollution problems quickly and forcefully, and it can enhance the threat degree to regulate the local government's behaviors.

Fourth, it should reform the local government's performances evaluation. In fact, in the law on prevention and control of water pollution, it has been provided that the local government and its responsible person depend on the target of protecting the water environment to get promotion. However, in real life, this law could not guarantee that the leaders implement the protection polices well. It is advocated that the local government be implemented a one-vote policy of water resources quality. In order to achieve sustainable development and a secure society, institutions and methodologies for water protection should be reformed ${ }^{[7]}$. The majority of stakeholders are able to participate in the water resources protection and supervision effectively, especially in the water scarcities regions.

\section{Acknowledgements}

This paper is supported by the National Natural Science Foundation of China (No. 70973010). 


\section{References}

[1]Najmeh Mahjouri, Mojtaba Ardestani.A game theoretic approach for interbasin water resources allocation considering the water quality issues.Environ Monit Assess.167(2010), p.527-544.

[2]Zhang weiying. Game theory and information economics.Shanghai: Shanghai people's publishing house.(1996)

[3]Wanlinwei. Analysis and suggestions for enterprise environmental protection investment game under the concept of ecological civilization. Gansu Social Sciences.1 (2012), p.242-244.

[4]Molanqiong,yujianyuan. Analysis of the interests between central and local government in macro-control game. Commercial Times. 19 (2009),p.7-8.

[5]FAN Canghai .Analysis of Benefiting Game on Public Policy Formation of South-to-North Water Diversion Project in China. Science and Technology Management Research.17(2010),p.205-209.

[6]Kaveh Madani.Game theory and water resources. Journal of Hydrology. 381(2010),p.225-238.

[7]Lizhong Wang, Liping Fang, Keith W. Hipel. Basin-wide cooperative water resources allocation.European Journal of Operational Research. 190(2008), p.798-817. 